\title{
A EDUCOMUNICAÇÃO E OS SERTÕES DO SÉCULO XXI
}

\author{
Gislene MoreirA ${ }^{1}$
}

\begin{abstract}
RESUMO: O presente trabalho faz uma revisão histórica da relação entre comunicação e educação no semiárido nordestino, como ponto de partida para entender os avanços e desafios da educomunicação no sertão baiano. $\mathrm{O}$ texto se dedica, com base na economia política da comunicação e da cultura, a problematizar o percurso dos projetos, usos e sentidos das políticas educacionais e comunicacionais historicamente implantadas nos sertões do interior da Bahia. Entendendo os processos de popularização das Tecnologias da Informação e da Comunicação (TIC) na região como um fenômeno de expansão periférica do capital globalizado, o estudo indaga sobre os riscos de conceitos neocolonizadores na área e propõe a educomunicação de raiz como caminho de educação pela comunicação contextualizada e transformadora.
\end{abstract}

Palavras-chave: Educomunicação. História da educação. Tecnologias da informação e da comunicação. Semiárido.

\section{EDUCOMMUNICATION AND THE BACKLANDS IN THE $21^{\text {ST }}$ CENTURY}

ABSTRACT: This paper presents a historical review of the relationship between communication and education in the northeastern semi-arid region, as a starting point for understanding the advances and challenges of the educommunication in the backlands of the Brazilian state of Bahia. Based in the political economy of communication and culture, the text problematizes the course of the educational and communicational projects, uses and meanings historically implanted in the countryside backlands of Bahia. Considering the popularization processes of the Information and Communication Technologies (ICT) in the region as a peripheral expansion phenomenon of the globalized capital, the study inquires about the risks of neocolonization concepts in the area, and proposes the educomunication roots as a path for education through contextualized and transformative communication.

Keywords: Educommunication. History of education. Information and communication technologies. Semi-arid.

1. Universidade do Estado da Bahia - Departamento de Ciências Humanas e Tecnologias da Chapada Diamantina - Seabra (BA), Brasil. E-mail: ggomes@uneb.br 


\section{LA EDUCOMUNICACIÓN Y LOS SERTÕES DEL SIGLO XXI}

RESUMEN: El presente trabajo hace una revisión histórica de la relación entre comunicación y educación en el semiárido del noreste brasilero, como punto de partida para entender los avances y desafíos de la educomunicación en el sertão del estado brasilero de Bahía. El texto se dedica, a partir de la economía política de la comunicación y de la cultura, a problematizar el trayecto de los proyectos, usos y sentidos de las políticas educacionales y comunicacionales históricamente implantadas en el interior de Bahía. Entendiendo los procesos de popularización de las Tecnologías de Información y Comunicación (TIC) en la región como fenómeno de expansión periférica del capital globalizado, el estudio indaga sobre los riesgos de los conceptos neocolonizadores en la área. El texto propone la educomunicación con raíces como camino para la educación por la comunicación contextualizada y transformadora.

Palabras-clave: Educomunicación. Historia de la educación. Tecnologías de la información e de la comunicación. Semiárido.

\section{Introdução}

$\mathrm{H}$

istoricamente, os sertões foram associados às zonas distantes ao projeto civilizatório da colonização e o interior nordestino foi considerado sinônimo de atraso e miséria. Nos anos 1930, Luís Gonzaga e Zé Dantas cantaram Riacho do Navio e relataram esse lugar como um sertão "sem rádio e sem notícias das terras civilizadas".

No novo milênio, os sertões não são mais os mesmos. Desde o fim dos anos 1970, essa zona entrou no projeto de modernização capitalista e se reinventou como um semiárido de possibilidades. A partir dos anos 2000, a região tem crescido mais que a média nacional, com cidades densamente povoadas, urbanizadas e imersas num mar de tecnologias.

O mapa do semiárido mais populoso do planeta abrange 1.134 municípios, em nove estados brasileiros, com cerca de 22 milhões de habitantes (ASA BRASIL, [s. d.]). Mais de $60 \%$ dessa população tem menos de 25 anos. São cerca de 9,4 milhões de jovens sertanejos com acesso à Internet, dos quais 46\% utilizam as redes sociais para realizar alguma atividade escolar ${ }^{1}$. Nas residências, $85 \%$ da população têm acesso ao celular e quase todas as casas (98\%) têm televisão e rádio. Os conectados à Internet ultrapassam $30 \%{ }^{2}$.

Apesar dos avanços e das tentativas de inclusão digital, a região ainda abriga 6,5 milhões de analfabetos. Indicadores educacionais, nas últimas décadas, como o Índice de Desenvolvimento da Educação Básica (Ideb) e as taxas de abandono no Ensino Fundamental, apontam tímidas melhorias. Todavia, os desafios da escola sertaneja ainda são enormes. Por exemplo, enquanto a taxa de distorção idade-série no Ensino Fundamental é de 14,3\% no Sudeste, no Nordeste ultrapassa 25\% (UNICEF, 2017).

Metade dos analfabetos do país vive no semiárido e um em cada dois sertanejos ainda não completou o Ensino Fundamental. Nas escolas, falta conexão (menos de 5\% acessam a Internet), além de banheiros. Mais de 20 mil instituições públicas de ensino da região semiárida sofrem com falta d'água e 450 mil estudantes da zona rural não têm saneamento básico nos locais onde estudam (ASA BRASIL, [s. d.]).

Este estudo entende que tal cenário reflete uma globalização neocolonizadora, entendida como a importação de tecnologias e saberes descontextualizados, os quais atendem a interesses de grandes corporações 
financeiras na conquista de novos mercados. Isso está diretamente relacionado à convergência digital, um fenômeno de confluência técnica e produtiva dos setores da radiodifusão, telecomunicações e informática, que deve ser entendido dentro do processo de avanço capitalista e da luta de classes (BOLAÑO; VIERA, 2012).

Nos novos sertões, a chegada dessa globalização midiática impõe o consumo tecnológico e de conteúdos produzidos pelos grandes conglomerados informacionais, sem romper com as antigas lógicas e estruturas de poder (MOREIRA, 2018). Para entidades que atuam com a educação sertaneja, como a Rede de Educação do Semiárido (Resab), a precariedade pedagógica das escolas da região não diz respeito apenas à infraestrutura e à falta de equipamentos tecnológicos, mas se reflete na importação de conteúdos e modelos que ignoram e estigmatizam a realidade local (RESAB, 2006). A Resab, entre outros movimentos educacionais do semiárido, é referência de denúncia e ruptura com esse paradigma de precariedade pedagógica em contextos adversos, apresentando uma série de experiências e iniciativas de inovação em educação contextualizada dentro de um cenário de disputas políticas.

Mészaros (2005) também insere a escola como espaço de disputas, que, apesar das utopias, é produto de uma ordem social e dos interesses dos grupos hegemônicos que a conceberam. Este estudo entende que a distância entre os avanços tecnológicos e a manutenção dos baixos índices educacionais no semiárido reflete, na educação, as contradições da acelerada inserção da região no capitalismo globalizado. Além disso, a precariedade do modelo pedagógico sertanejo, com ou sem tecnologia, reflete as heranças do projeto cultural fixado desde os tempos da colonização.

Este trabalho busca identificar as fragilidades dos atuais modelos pedagógicos que unem mídia e escola no sertão baiano, refazendo as trajetórias da comunicação e da educação no território semiárido. A ideia é contextualizar esse cenário nos marcos históricos do coronelismo, do patriarcado e do racismo que se estabeleceram desde as origens do povoamento regional.

A análise faz uma revisão histórico-bibliográfica da educação e da comunicação no semiárido, utilizando ferramentas epistemológicas geradas a partir dos marcos da decolonialidade (QUIJANO, 2010) e do materialismo histórico-dialético da economia política da comunicação e da cultura. Essas releituras foram associadas a vinte anos de práticas de educomunicação ${ }^{3}$ junto a organizações sociais do semiárido baiano, como ponto de partida para ensaiar uma proposta de educomunicação radicalmente comprometida com a transformação e a autorrealização dos povos sertanejos.

\section{Matrizes do Letramento, da Comunicação e da Cultura nos Sertões}

A Carta de Pero Vaz de Caminha em 1500 anunciou o interior do país como sinônimo de "desertão". O conceito definia os espaços distantes, inóspitos e "despovoados" pelo projeto colonizador. Aos poucos, o interior do Nordeste foi fixando essas noções historicamente e, entre as consequências desse marco, estão o isolamento regional, o extermínio e/ou a assimilação das populações indígenas, a normalização da escravidão negra e a ocupação violenta do território sertanejo (MOREIRA, 2018).

As missões católicas para a civilização dos indígenas representaram a síntese da imposição religiosa e idiomática sobre as populações autóctones e/ou escravizadas e fizeram parte desse repertório cultural de dominação. $\mathrm{O}$ ensino nas missões, seguido da violência dos conquistadores, foi a primeira experiência de letramento (SENA, 2014).

Esse modelo amadureceu nos sertões como resultado marginal de uma economia dependente de criação de gado para abastecimento dos núcleos açucareiros. Depois da falência dessa matriz agroexportadora, em quase 300 anos de estagnação e isolamento, estabeleceram-se traços culturais verticalizados, como o 
machismo e o silêncio, que refletiram os códigos de poder de uma estrutura social rígida e desigual, pautada pelo latifúndio e pelo patriarcado (MOREIRA, 2018).

$\mathrm{Na}$ educação, esse marco se apresentou na ausência de instituições de ensino formal por mais de três séculos, tendo a educação régia na Bahia se limitado à capital (CARDOSO, 2002). As primeiras unidades do interior foram as Escola Normais de formação de professores, no fim do século XIX, situadas em grandes núcleos urbanos, como Feira de Santana, e, em sua maioria, dirigidas por instituições religiosas.

A formação de professores se realizava em locais provisórios, com estruturas precárias ou inadequadas, e era destinada ao ensino do idioma e das regras gramaticais da escrita ocidental. Essas escolas fizeram parte das políticas que estabeleceram o letramento como lugar de poder e privilégio. Eram prioritariamente destinadas aos "filhos dos leões", os descendentes dos coronéis do semiárido (CHATES, 2014). Além de poucas e restritas, tais escolas tinham a missão de educar as elites locais nas tradições cultural, religiosa e política (VILELA, 2003).

A adequação da carreira do magistério ao projeto hegemônico requeria que os professores apresentassem "bom comportamento moral, político e religioso" (TANURI, 2000). O currículo escolar refletia os interesses dos grupos dirigentes (MENEZES, 2010). Como exemplo, a estrutura patriarcal se reproduzia nas Escolas Normais por meio de uma forte divisão de gênero, em que as mulheres tinham disciplinas diferenciadas, como "prendas domésticas" (LUZ; SILVA, 2008). Nesse projeto, a educação infantil foi assumida como responsabilidade feminina, estendendo os cuidados com o lar ao magistério.

$\mathrm{Na}$ legitimação institucional dos coronéis, no processo de "pacificação" e municipalização do interior nordestino, iniciado por Getúlio Vargas, tais escolas serviram para a formação técnica e burocrática de herdeiros e aliados, aumentando sua capacidade de direção dos "currais" por meio de uma aristocracia letrada.

Nem sequer o projeto modernizador da educação no país, que se dedicou às metas de profissionalização e formação de mão de obra minimamente qualificada, rompeu com essa prática elitista. Nem mesmo Anísio Teixeira, um dos mais progressistas na educação pública da Bahia, alterou as marcas elitistas da formação educacional no semiárido (ROCHA, 2005). Em seu projeto pedagógico da Escola Nova, a formação era muito mais destinada à profissionalização e à inserção no modelo da modernização planejado a partir do Sudeste do que ao fomento de práticas contextualizadas.

Essa visão "civilizatória" justificou a ação tutelar do Estado e das elites locais junto à população sertaneja, considerada uma massa de analfabetos, miseráveis, e inaptos ao pensar. $\mathrm{O}$ argumento da incapacidade racional dos sertanejos serviu como subterfúgio para os massacres locais, como o de Canudos (1897), e explicou a manipulação coronelista quanto ao argumento da seca.

$\mathrm{Na}$ área da comunicação, por séculos, permaneceu no sertão um vazio, marcado por estruturas verticalizadas e hierárquicas, pela ausência de veículos e de canais comunicativos e, principalmente, pela violência dos coronéis e o mutismo da maioria da população (MOREIRA, 2018).

\section{Aproximações entre Mídia e Escola na Modernização Sertaneja}

A partir dos anos 1980, novas lógicas de educação e poder se instalaram no território semiárido como parte do projeto de mecanização do campo e de expansão das fronteiras agrárias pela Ditadura Militar. Um dos principais reflexos desse período foi o modelo pedagógico e cultural que aproximou mídia e educação de massa. Acordos entre o Ministério da Educação e Cultura (MEC) e a Agência para o Desenvolvimento Internacional dos Estados Unidos (USAID; do inglês, United States Agency for International Development) 
implantaram mudanças no desenho educacional e criaram metas ambiciosas de alfabetização em massa, que refletiam o conceito tecnicista da Comunicação para o Desenvolvimento (WAISBORD, 2001).

A Comunicação para o Desenvolvimento foi uma aposta teórica, metodológica e técnica que surgiu motivada pelas agências internacionais norte-americanas na Guerra Fria para o fomento do uso massivo dos meios como estratégia de modernização de países "subdesenvolvidos" e para a influência do modelo capitalista (GUMUCIO-DRAGON; TUFTE, 2006).

No Brasil, iniciativas como o Mobral (Movimento Brasil de Alfabetização) e o Projeto Minerva inauguraram o uso de rádio, televisão e cinema como complementares ao letramento e à educação supletiva de jovens e adultos (BRASIL, 1967). Tais inovações fizeram parte do projeto modernizador de expansão do agronegócio no semiárido, em uma tentativa de mínima qualificação da mão de obra, bem como de eliminação dos conflitos no campo.

A ideia balizou também os investimentos em infraestrutura comunicacional na região, como a instalação de rádio e TV, além das redes de telecomunicações nos anos 1980. É interessante destacar que as concessões das mídias na região inauguraram o "coronelismo eletrônico", fenômeno em que a propriedade dos meios de comunicação refletia a dominação latifundiária (LIMA; LOPES, 2008). A massificação dos meios fazia parte da construção de hegemonia nos sertões, a qual deixou de ser pautada na violência e no mutismo e passou a adotar a estratégia de dominação cultural, mesclando mídias de massas com popularização do consumo e do ensino (MOREIRA, 2018).

Na redemocratização do país, esse processo culminou com os avanços e as metas educacionais da Constituição de 1988, que universalizou a educação pública. Junto à ação de organismos internacionais, como o Banco Mundial e o Banco Interamericano de Desenvolvimento (BID), o país estabeleceu metas que impactaram na região.

Até o fim dos anos 1990, prevaleciam, no interior nordestino, escolas informais, isoladas e restritas. A população de jovens e adultos analfabetos superava os 50\%. Mais de 350 mil crianças e adolescentes entre 10 e 14 anos estavam fora da escola. A infraestrutura de educação atendia menos de $20 \%$ das necessidades de formação básica da região (PEREIRA; REIS, 2006). A formação docente tratava, principalmente, da importação de conceitos, conteúdos e modelos externos (CHATES, 2014; SENA, 2014).

Para a emergente sociedade civil que se formou no território em resposta à modernização autoritária, faltavam salas de aula e projeto pedagógico. Esses atores emergiram nos anos 1970, com o aumento dos conflitos no campo, e se organizaram como Comunidades Eclesiais de Base (CEB), sindicatos rurais e movimentos de luta pela terra. Para eles, o modelo de educação que estava sendo implantado, homogeneizava o ensino a partir dos padrões do Sudeste, desconsiderava as especificidades do campo e ignorava os saberes locais.

Esses movimentos sociais produziram inovações pedagógicas de "convivência com o semiárido". Articulados em eventos e redes voltados à educação do campo ${ }^{4}$, construíram marcos e modelos educacionais mais progressistas para a região, buscando uma pedagogia contextualizada e a emancipação política (BATISTA, 2006; PEREIRA; REIS, 2006; SILVA et al., 2009).

Desde os anos 1970, tais atores experimentaram o uso das mídias como estratégia de inclusão pedagógica em uma série de iniciativas de comunicação popular e comunitária, como a criação de rádios e cartilhas. Por exemplo, o Setor Diocesano de Comunicação (Sedica) de Juazeiro da Bahia, nos anos 1980, fomentou uma equipe de comunicadores populares para atuarem como repórteres. Eles gravavam notícias sobre os conflitos do campo em suas comunidades em fitas cassete e os programas produzidos por eles iam ao ar na Emissora Rural de Petrolina. Esse material comunicacional era motivador de debates e produção educativa nos trabalhos de educação popular das CEB da região (OLIVEIRA, 2008). 
Tais iniciativas refletiam os "currículos" e percursos metodológicos desses movimentos sociais, que misturaram formação de lideranças políticas com estudo crítico da História, valorização dos saberes populares e do trabalho na roça, convivência com o semiárido e acesso mínimo aos códigos do letramento e da comunicação. Nesse projeto alternativo, o foco era a emancipação dos sujeitos, o fortalecimento das identidades locais, e das lutas sociais. Paulo Freire e seu método se tornaram a principal referência pedagógica de comunicação popular (FREIRE, 1985).

\section{A Educomunicação Chega ao Sertão}

O projeto do Mobral e a proposta dos movimentos sociais representam dois modelos pedagógicos muito diferenciados de usos da comunicação na educação. No primeiro, o ensino pelas ondas radiofônicas é baseado no modelo tecnicista e verticalizado norte-americano. O rádio é uma ferramenta de emissão dos conteúdos definidos por especialistas.

Já o modelo de Paulo Freire dá ênfase à horizontalidade. A tecnologia em questão, o rádio, funciona como mediador das relações de produção de conhecimento. Na experiência de Juazeiro, por exemplo, os repórteres traziam o problema de suas comunidades gravado em fitas cassete e aprendiam as técnicas como tática pedagógica de compartilhamento de experiências. Juntos, discutiam os problemas, pensavam em soluções e se fortaleciam. Pedagogicamente, esse modelo valorizava o território, os saberes do educando e a construção de projetos coletivos. Tais iniciativas se espalharam por todo o semiárido nordestino e se aproximavam do então emergente conceito de educomunicação.

O termo educomunicação foi usado pela primeira vez por Mário Kaplún (1998) para designar voluntários e profissionais que experimentavam o fazer de mídias comunitárias. Desde então, passou a descrever a ideia e a prática dos usos críticos e pedagógicos dos meios de comunicação como estratégia de criação de "ecossistemas comunicativos". Martín-Barbero (2011), um dos pioneiros na conceituação da educomunicação, explica que esses ecossistemas são os sentidos dados às novas dinâmicas sociais geradas pela relação com as novas tecnologias e pela circulação dos saberes para fora das barreiras tradicionais, como a geografia e os muros da escola.

Em geral, o debate sobre a educomunicação pretende ir além dos letramentos digital ${ }^{5}$, e midiático ${ }^{6}$, pois aposta na mediação como tática de reapropriação cultural das mídias pelos grupos minoritários, valorizando as produções comunitária, popular e alternativa como projeto de enfrentamento e contrahegemonia (PERUZZO, 2017). No Brasil, o conceito de educomunicação foi fixado e desenvolvido, em grande medida, pelo Núcleo de Comunicação e Educação da Universidade de São Paulo (NCE-USP), a partir do projeto Educom Radio, de implantação de rádios em escolas do Mato Grosso e de São Paulo. Desde essa iniciativa, a aposta em ecossistemas comunicativos exige espaços abertos e democráticos (SOARES, 2008).

Nesse sentido, as iniciativas desenvolvidas pelos movimentos de convivência com o semiárido se alinhavam com esse projeto. A questão é que a maioria dessas experiências permaneceu fora das escolas regulares (ROSSETTI, 2005). Apenas em meados dos anos 2000 os conceitos de educomunicação e as novas tecnologias chegam às políticas públicas educacionais no semiárido.

\section{A Escola Sertaneja dos Anos 2000}

A escola dos sertões ingressou nos anos 2000 vivenciando, de maneira acelerada, três grandes revoluções fundamentais: a) tecnológica-comunicativa, com a popularização acelerada do acesso às mídias; 
b) educacional massiva, dirigida às metas de universalização do ensino público; e c) cultural-produtiva, com o progressivo afastamento das novas gerações da base econômica agrária tradicional para modos de vida mais urbanizados. Essas transformações afetaram diretamente o ambiente escolar e se relacionam com giros ainda mais amplos.

O giro político nacional (2003-2016) permitiu a emergência de programas e projetos de educação e novas tecnologias, que priorizaram o semiárido e o debate da convivência. As eleições de Lula (2002-2006) e Dilma (2010-2014) foram acompanhadas de perto pelos movimentos sociais sertanejos, que impulsionaram iniciativas como o Programa Nacional de Educação na Reforma Agrária (Pronera) voltado às zonas de assentamentos; as Conferências Nacionais de Educação, que incentivaram a participação e a democratização das metas de ensino; e o PNAIC (Pacto Nacional pela Alfabetização na Idade Certa), voltado à redução do analfabetismo e da precariedade da educação no interior do Nordeste.

Também se destacou a interiorização dos Ensinos Técnico e Superior, pela criação e/ou a ampliação de Institutos Federais e universidades, como a Universidade Federal do Cariri (Ufca), a Universidade do Vale do São Francisco (Univasf), a Universidade Federal Rural do Semiárido (Ufersa), entre as mais de 130 instituições públicas criadas na região em treze anos de gestão.

Na educação básica, as políticas educacionais petistas regulamentaram o sistema de municipalização da educação nacional ${ }^{7}$, baseado no regime de colaboração entre a União, os estados e os municípios, iniciado por Fernando Henrique Cardoso e voltado à melhoria dos índices da educação no país. No semiárido, essa estratégia fortalecia as práticas coronelistas municipais, que encontraram nos recursos para a educação, como Fundo de Manutenção e Desenvolvimento da Educação Básica e de Valorização dos Profissionais da Educação (Fundeb), nova estratégia de manutenção das antigas estruturas (OLIVEIRA, 2009).

Inserida nessa proposta estava grande diversidade de programas especiais, entre os quais o Projeto Mais Educação ${ }^{8}$, dirigido à formação complementar no turno oposto ao ensino formal (MARQUES; MENDES, 2007). No macrocampo Comunicação e Uso de Mídia, utilizou-se o suporte teórico da educomunicação9.

Nessa área, a iniciativa oferecia acompanhamento pedagógico, comunicação e uso de mídias, cultura digital e tecnológica, entre outras formações escolhidas por cada escola (TINÉ, 2017; PRÓSPERO, 2013). Estima-se que a ação tenha atingido mais de 4 milhões de estudantes, em cerca de 50 mil estabelecimentos de ensino por todo o país. Para Próspero (2013) e Tiné (2017), o Mais Educação constituiu teste positivo para a educomunicação como política pública nacional. A iniciativa foi apontada como resultado direto do NCEUSP quando o ministro Fernando Haddad foi prefeito de São Paulo e implantou um piloto na capital paulista. No Ministério da Educação, Haddad expandiu o projeto em nível nacional entre 2005 e 2010 (COSTA, 2016; PRÓSPERO, 2013).

Além do Mais Educação, grande diversidade de políticas públicas de fomento à conectividade digital foi implantada no semiárido no mesmo período, como os Pontos de Cultura; o Cinturão Digital do Ceará, com expansão de cabeamento de fibras óticas; as metas do Plano Nacional de Banda Larga (PNBL); e centenas de infocentros.

Na Bahia, o governo do estado apresentou, em 2010, o programa Ensino Médio com Intermediação Tecnológica (EMITec), voltado a áreas com "populações carentes" e "regiões remotas", como estratégia de educomunicação e desenvolvimento regional (SANTOS; ARAÚJO, 2017). O projeto investiu em teleaulas produzidas em Salvador, acompanhadas por tutores de comunidades rurais de 140 municípios baianos, além de investir na formação de mais 16 mil alunos.

No ensino regular, o governo baiano implantou o Projeto de Produções Visuais e Estudantis (Prove). A iniciativa promoveu concursos audiovisuais de filmes produzidos pelos estudantes. Os vídeos selecionados nos Núcleos Territoriais Educacionais participavam de uma mostra, que, em 2018, estava na $7^{\text {a }}$ edição. 
A iniciativa buscava fomentar o protagonismo estudantil e a experiência fílmica no ambiente escolar. As produções eram feitas pelos alunos, sem vinculação direta com as disciplinas e os conteúdos regulares, tampouco com o projeto político pedagógico. Nesses núcleos, é comum chamar o resultado dessa produção de educomunicação.

Todas essas experiências são apresentadas como potencial uso da comunicação e das mídias na escola sertaneja, bem como promessa de solução para os históricos déficits educacionais. Todavia, bcomo mensurar os resultados e os alcances?

\section{Impactos e Limites}

O impacto dessas iniciativas no semiárido ainda não foi medido, tampouco foram encontrados estudos que analisem o alcance dessas experiências em profundidade. Ainda são poucos e recentes os esforços nesse sentido, como o de Pedroza (2016), que investigou a aplicação do programa Mais Educação em Juazeiro da Bahia. Ele identificou que apenas uma das dezesseis escolas que haviam aderido ao componente de rádio mantinha atividades regulares de educomunicação.

Em sua análise sobre a política considerada de referência no país, Próspero (2013) também encontrou desafios como os apontados por Pedroza em Juazeiro. A autora atribui os problemas à complexidade da implementação de política pública educomunicacional no Brasil, devido a suas especificidades regionais. Pelo semiárido, são comuns os depoimentos de educadores, secretarias de educação municipal e jovens sobre os problemas de descontinuidade das experiências ou o isolamento das práticas educomunicativas no interior baiano.

Em geral, as poucas iniciativas refletem mais o resultado dos esforços pessoais dos professores ou gestores e estão mais vinculadas ao desejo dos alunos do que a projetos político-pedagógicos. Não são poucos os relatos que apontam a falta de familiaridade dos docentes em se aproximar das novas tecnologias midiáticas como prática educacional cotidiana. Mesmo o Mais Educação e o Prove, que buscaram envolver os alunos em práticas produtivas de educomunicação, apresentaram-se como projetos paralelos ao currículo regular, fora das rotinas e práticas da sala de aula.

O problema não é só a falta de recursos ou de formação. Experiências como o EMITec, com altos investimentos, privilegiaram o repasse de conteúdos externos. Essa apropriação de modelos teóricos, pedagógicos e tecnológicos que pouco dialogam com o semiárido é uma constante. Isso acaba gerando ambientes de aprendizagem que promovem sertões conectados tecnologicamente, mas "desterritorializados", sem conexão com sua realidade.

Em relação à contextualização das experiências, a produção desses conteúdos parece desvincular o uso dos meios com a leitura crítica das mídias e dos mundos, com os debates políticos e as pautas dos movimentos sociais locais. É difícil encontrar projetos com metas de transformação da realidade local. Muitas dessas iniciativas atuam como repetição tecnológica e espetacularização do ensino (MESSIAS, 2011). A maioria reflete uma perspectiva colonizadora, distanciada do pensamento crítico, e que perpetua estruturas verticalizadas de comunicação e poder.

Viana (2017) propõe pensar esses limites e desafios como aposta na educomunicação possível, a qual está diretamente relacionada com as estruturas de cada ecossistema comunicativo. Com um olhar macro, é difícil esperar ambientes democráticos e abertos em experiências que foram gestadas dentro de uma política de municipalização favorecedora das estruturas verticalizadas e da lógica coronelista.

Nesse sentido, pode-se apontar que os novos sertões ainda estão imersos em escolas desconectadas. Além dos baixos índices de conectividade digital, em que faltam equipamentos e redes wireless, também faltam metodologias, políticas e projetos que conectem a escola a suas raízes e seu contexto. 


\section{Por uma Educomunicação Sertaneja Decolonial}

Nos sertões das revoluções tecnológica-comunicativa, educacional massiva e cultural-produtiva, a educomunicação aparece como aposta inovadora na formação das novas gerações de sertanejos. Apresenta-se como projeto potencial, que aproveita as brechas midiáticas e tecnológicas para ultrapassar os antigos limites dos "desertões", de suas escolhas e escolas.

Contdo, para conectar a nova escola sertaneja ao mundo, faz-se necessário reconectá-la com o território onde está inserida. A partir dessa compreensão, aventuramo-nos a propor a educomunicação de raiz, como um fazer educomunicativo que valoriza os vínculos com a terra e as matrizes sertanejas na geração de espaços e produtos comunicativos críticos e contextualizados. Essa proposta é, antes de tudo, um chamado à construção de escolas decoloniais.

Por escolas decoloniais entende-se o ambiente de ensino-aprendizagem que constitui território pedagógico vivo e ativo na transformação e na construção de uma nova história nos sertões, buscando constantemente fomentar rupturas com os modelos pedagógicos conservadores; que se compromete com a valorização das lutas e saberes dos povos tradicionais; e que tem currículo permeado pela leitura crítica do mundo e por práticas de solidariedade e diálogo com a realidade local. Nesse projeto, a educomunicação de raiz nasce como um desejo, uma utopia, que, dentro da práxis educacional, situa-se como projeto de poder em disputa e busca radicalizar o modelo político-pedagógico nas escolas e as políticas públicas na área.

Com base na concepção da proposta, é necessário contextualizar os conceitos e práticas da educomunicação, reconhecendo que o projeto de gerar ecossistemas comunicativos horizontalizados, abertos e democráticos está imerso nas heranças do coronelismo, do racismo e do patriarcado. No plano micro, do ambiente escolar, a educomunicação precisa ser pensada como ruptura das matrizes históricas dos sertões, as quais se perpetuam na escola. Isso significa reconhecer que gestores e educadores estão em posições de assimetria com os educandos, bem como que as estruturas de comunicação são verticalizadas, sendo necessário pensar estratégias de superação dessas barreiras e desses conflitos.

$\mathrm{Na}$ busca pela ruptura dos modelos verticalizados de enunciação, o educador deve se entender como facilitador de processos e mediador de diálogos, não transmissor de conteúdos. Não se trata de sentar em círculo ou permitir a fala dos educandos. O processo de formação constitui, em si mesmo, uma busca constante por relações horizontalizadas que valorizem o potencial de cada aluno na construção de sua própria história. O processo educomunicativo, para além do ensino dos meios, é um canal de diálogo e construção de novos modelos de interação e participação educacional, social e política.

A educomunicação de raiz deve emergir entendendo que, historicamente, as políticas de letramento e escolarização no semiárido fizeram parte do modelo colonizador, que manteve os sertanejos aleijados da terra, da escrita, da leitura de mundo e das posições de fala. A escola dos sertões do século XXI precisa ir além de metas e índices de universalização do ensino para constituir espaço de produção do pensar crítico e transformador.

Nessa aposta, o diálogo com a terra e a realidade local assume a centralidade do projeto. Inseridas em uma pedagogia do território, as comunidades locais emergem como espaço privilegiado de construção dos saberes e das redes de colaboração, em que a escola é mais um dos atores em interação. Em termos metodológicos, a produção educomunicativa na escola deve priorizar a construção de estéticas, formatos e conteúdos que dialoguem com a memória, com os atores, com os conflitos e com a busca de soluções para seus próprios dilemas.

Tal escola se conecta com as raízes da identidade local e dos povos tradicionais, historicamente aleijados dos espaços de enunciação. Por isso, ela precisa estar atenta à história, aos valores e aos discursos 
dos agricultores familiares, das mulheres, dos grupos indígenas e quilombolas e, em particular, de sua relação com a terra e com o ambiente sertanejo.

Nessa aposta educomunicacional, a ênfase não é no produto midiático, tampouco na transmissão de conteúdos e plataformas, mas na criação de redes de saberes e relações sociais, baseadas nas trocas e nas interações críticas e afetivas com o território local e com o mundo. A proposta é de resgate do conceito básico da comunicação como interação e transformação de atores críticos, proativos e conscientes do seu papel no território em que vivem.

Nesse sentido, a educomunicação emerge como conjunto de práticas de mediação que promovem a interação com as mídias como estratégia de transformação para um sertão mais justo. Ela é uma opção metodológica e política que permite dar sentido à produção midiática e à vida dos educandos, em uma sociedade cada vez mais pautada por valores externos da sociedade de consumo.

O convite é para ouvir o território, a partir da escuta dos educandos e de suas leituras de mundo (Que canais de comunicação acessamos? Que músicas escutamos? Por que as escutamos?), e partir desses códigos, que nos são familiares, aprender juntos sobre o mundo e como transformá-lo. Essa aproximação funciona como mediação e é ponto de partida para as perguntas geradoras, que apontava Paulo Freire. Que discursos se repetem nesses produtos? Como sua comunidade aparece? Como você se vê neles? Dessa leitura dialogada sobre discursos e as imagens, podem surgir ferramentas poderosas de recepção crítica das mensagens midiáticas. Essa leitura pode, também, apontar novas perspectivas para a geração de uma produção comunicacional autêntica e libertadora, que rompa com os estereótipos do desertão ou das imposições da sociedade de consumo.

Outra chave de leitura é perguntar o que se diz sobre as mulheres? É necessário lembrar que, na história dos sertões, a feminilização do magistério delegou a elas o papel de educadoras. Entretanto, muitas das mulheres que assumem tal função ainda vivenciam violências cotidianas e estão longe dos espaços de poder. O que se diz, também, sobre os negros? Assim, abrem-se outros cenários de debate sobre a verticalização das falas e estéticas.

Essa ampliação crítica de horizontes deve se refletir em uma produção educomunicativa com conteúdos, sotaques, estéticas e características próprias, que vão além da valorização regional. A educomunicação de raiz se conecta com os saberes dos ancestrais e a cultura local como fonte de inspiração, ressignificação e construção das identidades contemporâneas. No passado, os sertanejos transformaram a chita, o forró e a comida da roça de símbolos de pobreza em códigos da festa e inventividade. Na contemporaneidade, as novas tecnologias neocolonizadoras podem ser reapropriadas como instrumentos criativos de libertação e interação em redes globalizadas de ampliação de "outras convergências".

Portanto, no plano macro, a educomunicação de raiz emerge como projeto de política pública que vai além do plano educacional e está diretamente envolvido na democratização dos meios de comunicação. Ela busca a promoção do acesso, da produção, da difusão e da gestão da mídia, entendendo a comunicação como direito humano. O aprendizado democrático e contextualizado dos meios no ambiente escolar é parte inerente da sociedade da informação.

Para além da reprodução tecnológica, a educomunicação de raiz é um projeto de poder decolonial, que atua na desconstrução dos modelos de concentração do poder e da fala. Por isso, trata-se de projeto macro de sociedade, que extrapola os muros da escola para se inserir nos debates sobre direitos humanos, democracia, concentração midiática e liberdade de expressão. Ela trata de um projeto de mundo, que fala de utopias e lutas por outros sertões e comunicações possíveis. 


\section{Notas}

1. Estudo realizado pelo Comitê Gestor da Internet no Brasil (CGI.br), por meio do Centro Regional de Estudos para o Desenvolvimento da Sociedade da Informação (Cetic.br) do Núcleo de Informação e Coordenação do Ponto BR (NIC.br). Dados disponíveis em: http://cetic.br/pesquisa/educacao/indicadores. Acesso em: março 2018.

2. Pesquisa Nacional de Amostra Domiciliar (PNAD). Disponível em: https://agenciadenoticias.ibge.gov.br/agencia-noticias/2013agencia-de-noticias/releases/20073-pnad-continua-tic-2016-94-2-das-pessoas-que-utilizaram-a-internet-o-fizeram-paratrocar-mensagens.html. Acesso em: mar. 2018.

3. Experiência de rádio comunitária junto às Comunidades Eclesiais de Base, nos anos 1990; implantação dos programas de Comunicação do MOC (Movimento de Organização Comunitária); e assessoria a diversas entidades em atuação no semiárido, como UNICEF, ASA BRASIL etc., entre 2000 e 2008. Nos últimos anos, desde projetos de pesquisa e extensão na Universidade do Estado da Bahia (Uneb), a autora acompanha a ação de comunicação popular da Comissão Pastoral da Terra (CPT) e da Teia dos Povos, entre outros.

4. I Encontro Nacional de Educadoras e Educadores da Reforma Agrária (ENERA), em 1997; I Conferência Nacional por uma Educação do Campo, em 1998; criação da Rede de Educação para o Semiárido (RESAB) e das Diretrizes Operacionais da Educação do Campo, nos anos 2000 (PEREIRA; REIS, 2006).

5. O letramento digital aposta nas práticas sociais de leitura e escrita realizadas por meio das ferramentas digitais (SOARES, 2006; BORGES, 2017)

6. O midiático se refere às novas modalidades de leitura e escrita, que incorporam outros saberes, como o audiovisual (SETTON, 2010).

7. Focou-se em medidas como o Plano de Desenvolvimento da Educação (PDE), o Índice de Desenvolvimento da Educação Básica (IDEB) e o Plano de Metas Compromisso Todos pela Educação.

8. Portaria Interministerial n. 17/2007.

9. Disponível em: http://deitarare.educacao.sp.gov.br/Documentos/Comunica\%C3\%A7\%C3\%A3oeusodemidias.pdf. Acesso em: ago. 2018.

\section{Referências}

ASA BRASIL. Educação contextualizada para a convivência com o semiárido, [s. d.]. Disponível em: http:// www.asabrasil.org.br/26-noticias/ultimas-noticias/3146-educacao-contextualizada-para-a-convivencia-como-semiarido. Acesso em: set. 2018.

BATISTA, M. S. O campo como território de conflitos, de lutas sociais e movimentos populares. In: BATISTA, M. S., SCOCUGLIA, A. C. Educação do Campo no Ensino Superior: Diálogo entre o popular e o científico. Brasília: Ministério do Desenvolvimento Agrário, 2006.

BOLAÑO, C.; VIEIRA, E. Economia Política da Internet: Sites de redes sociais e luta de classes. Manaus: Intercom, 2012.

BORGES, F. G. B. A construção de uma metodologia para o letramento digital. Raído, Dourados, v. 11, n. 25, p. 280-294, jan.-jul. 2017. https://doi.org/10.30612/raido.v11i25.5009

BRASIL. Lei n. 5.379. Brasília, 1967. Disponível em: http://www.planalto.gov.br/ccivil_03/leis/1950-1969/ 15379.htm. Acesso em: ago. 2018.

BRASIL. Documento da II Conferência Nacional. Por uma Educação do Campo. Brasília, 1999.

CARDOSO, T. F. L. As Aulas Régias no Brasil. In: CARDOSO, T. F. L.; STEPHANOU, M.; BASTOS, M. H. C. (orgs.). Histórias e memórias da educação no Brasil, [s. 1.], [s. n.], 2002. (Volume I: séculos XVI-XVIII.) 
CHATES, T. Memórias das Escolas do Sertão. XIV Encontro Regional de História, 2014. Disponível em> http://www.erh2014.pr.anpuh.org/anais/2014/139.pdf. Acesso em: ago. 2018.

CITELLI, A. Comunicação e educação: Os movimentos do pêndulo. Revista Famecos - Mídia, Cultura e Tecnologia, Porto Alegre, v. 25, n. 3, 2018. http://doi.org/10.15448/1980-3729.2018.3.29914

CNE [Conselho Nacional de Educação]. Diretrizes Operacionais para a Educação Básica nas Escolas do Campo. Resolução n. 01/2002. Câmara de Educação Básica, 2002.

COMITÊ GESTOR DE INTERNET. Pesquisa sobre o uso das tecnologias de informação e comunicação no Brasil. São Paulo, 2014. Disponível em: http://www.cetic.br/media/analises/tic_domicilios_2014_coletiva_ de_imprensa.pdf. Acesso em: ago. 2018

COSTA, E. Educomunicação e Políticas Públicas: Um estudo comparativo entre as cidades de São Paulo e Rio de Janeiro. 7 SIMEDUC (Simpósio Internacional de Educação e Comunicação). Aracaju. 2016.

FREIRE, P. Extensão ou comunicação? São Paulo: Paz e Terra, 1985.

GUMUCIO-DRAGON, A.; TUFTE, T. (orgs). Antología de Comunicación para el Cambio Social. Lecturas históricas y contemporáneas. Nova York: Consórcio de Comunicación para el Desarrollo, 2006.

KAPLÚN, M. Una pedagogia de la comunicación. Madrid: Ediciones de la Torre, 1998.

LEÃO, F.; MELO, R.; GOMES, J. Pedagogia do território e juventudes do campo no Ceará. Fortaleza: Núcleo Tramas UFC. 2018.

LIMA, V. E.; LOPES, C. A. Rádios comunitárias: Coronelismo eletrônico de novo tipo (1999-2004). Observatório de Imprensa. São Paulo, 2008.

LUZ, J. A.; SILVA, J. C. História da Educação na Bahia. Salvador: Arcadia, 2008.

MARQUES, R. M.; MENDES, A. Servindo a dois senhores: As políticas sociais no governo Lula. Revista Katálysis, v. 10, n. 1, p. 15-23, 2007. https://doi.org/10.1590/S1414-49802007000100003

MARTIN-BARBERO, J. Desafios culturais: Da comunicação à educomunicação. In: CITELLI, A. O. (org.). Educomunicação: Construindo uma nova párea de conhecimento. São Paulo: Paulinas, 2011.

MESSIAS, C. Duas décadas de Educomunicação: Da crítica ao espetáculo. 2011. Dissertação (Mestrado em Ciências da Comunicação) - Escola de Comunicações e Artes, Universidade de São Paulo (USP), São Paulo, 2011. https://doi.org/10.11606/D.27.2011.tde-24032012-102952

MENEZES, A. C. S. Educação do campo semiárido: Fundamentos e práticas do currículo contextualizado. A educação brasileira em questão. Revista Temas em Educação, João Pessoa, v. 18-19, n. 1-2, p. 245-263, jan.-dez. 2009-2010.

MÉSZAROS, I. A Educação para além do Capital. São Paulo: Boitempo, 2005

MOREIRA, G. Sertões Contemporâneos: Rupturas e continuidades. Salvador: EdUFBA/EdUneb, 2018.

OLIVEIRA, R. Comunicação e cidadania às margens do São Francisco: Os correspondentes populares da Diocese de Juazeiro. São Paulo: UMESP, 2008. 
OLIVEIRA, D. A. As políticas educacionais no Governo Lula: Rupturas e permanências. Revista Brasileira de Política e Administração da Educação, v. 25, n. 2, p. 197-209, maio-ago., p. 197-209, 2009. https://doi. org/10.21573/vol25n22009.19491

PEDROZA, P. Comunicação e Educação: Um mapeamento das ações educomunicativas na rede pública de ensino de Juazeiro. Intercom, Sociedade Brasileira de Estudos Interdisciplinares da Comunicação XVII Congresso de Ciências da Comunicação na Região Nordeste, 2015. Disponível em: https://www. portalintercom.org.br/anais/nordeste2015/resumos/R47-1686-1.pdf. Acesso em: ago. 2018.

PEREIRA, V; REIS, S. Educar no Semiárido Brasileiro: O desafio de uma construção em rede. In: RESAB (org.). Caderno Multidisciplinar Educação e Contexto no Semiárido Brasileiro, Juazeiro, Selo Editorial RESAB, v. 1, n. 1, p. 61, maio 2006.

PERUZZO, C. K. Ideias de Paulo Freire aplicadas à comunicação popular e comunitária. Revista Famecos - Mídia, Cultura e Tecnologia, Porto Alegre, v. 24, n. 1, p. 01-16, jan-abr. 2017. http://doi. org/10.15448/1980-3729.2017.1.24207

PRÓSPERO, D. Educomunicação e políticas públicas: Os desafios e as contribuições para o Programa Mais Educação. 2013. 367 f. Dissertação (Mestrado em Ciências da Comunicação) - Escola de Comunicações e Artes, Universidade de São Paulo, São Paulo, 2013. https://doi.org/10.11606/D.27.2013.tde-30012014-105832

QUIJANO, A. Colonialidade do poder e classificação social. In: SANTOS, B. S.; MENESES, M. P. (orgs.). Epistemologias do sul. São Paulo: Cortez, 2010.

RESAB. Diretrizes da Educação para a Convivência com o Semiárido. I Conferência Nacional de Educação para a Convivência com o Semiárido. Juazeiro: Selo Editorial RESAB, 17-20 maio 2006.

ROCHA, A. O. Anísio Teixeira e a Escola Normal de Caetité/BA: Um projeto de formação de professores primários (1926-1941). 2005. Dissertação (Mestrado em Educação) - Programa de Pós-graduação em Educação, Universidade Federal de Santa Catarina, Florianópolis, 2005, Disponível em: https://repositorio. ufsc.br/handle/123456789/101709. Acesso em: 21 maio 2018.

ROSETTI, F. Mídia e Escola: Perspectivas para políticas públicas. São Paulo: Edições Jogo de Amarelinha, 2005.

SANTOS, L.; ARAÚJO, H. Ensino Médio com intermediação tecnológica (Emitec): Inclusão e escolarização na zona rural e regiões remotas. Salvador, Anais Anbed, 2017. Disponível em: http://www.abed.org.br/ congresso2017/trabalhos/pdf/153.pdf. Acesso em: ago. 2018.

SENA, R. O livro didático em questão: Um olhar a partir da perspectiva da Educação Contextualizada. In: CUNHA, A. R. B. A.; SANTOS, A. P. S.; PEREZ-MARIN, A. M. (orgs.). Educação Contextualizada para a convivência com o semiárido brasileiro: Debates atuais e estudos de caso. Campina Grande: INSA, 2014.

SETTON, M. G. Mídia e educação. Contexto: São Paulo, 2010.

SILVA, A. ; DANTAS, D.; BUENO, R. Construindo a educação para a convivência com o semiárido. Revista OKARA - Geografia em debate, João Pessoa, DGEOC/CCEN/UFPB, v. 3, n. 1, p. 1-222, 2009.-. (Edição Especial - II Seminário Luso-Brasileiro sobre Agricultura Familiar em Regiões com Risco de Desertificação.) Disponível em: https://periodicos.ufpb.br/ojs2/index.php/okara/article/view/9008. Acesso em: ago. 2018. 
SOARES, D. Educomunicação - O que é isto? Gens - Instituto de Educação e Cultura, 2006. Disponível em: http://portalgens.com.br/baixararquivos/textos/educomunicacao_o_que_e_isto.pdf. Acesso em: ago. 2018.

SOARES, I. O. Mas, afinal, o que é Educomunicação? Universidade de São Paulo: Núcleo de Comunicação e Educação da Universidade de São Paulo, 2008.

SOARES, M. Novas práticas de leitura e escrita: Letramento na cibercultura. Educação \& Sociedade, Campinas, v. 23, n. 81, p.143-160, dez. 2002.

TANURI, L. M. História da formação de professores. Revista Brasileira de Educação, n. 14, p. 61-88, maioago. 2000.

TINÉ, S. Z. S. A educação midiática e a educomunicação como elementos das políticas públicas de educação no Brasil: O Programa Mais Educação. In: SOARES, I. O.; VIANA, C. E.; XAVIER, J. B. (orgs.). Educomunicação e suas áreas de intervenção: Novos paradigmas para o diálogo intercultural. São Paulo: APBEducom, 2017.

UNICEF [Fundo das Nações Unidas para a Infância]. Caderno de Resultados edição 2013-2016. Selo Unicef Município Aprovado. Brasília: Unicef, 2017. Disponível em: http://www.selounicef.org.br/sites/default/ files/2019-05/SeloUNICEF-Resultados-2017-2020.pdf. Acesso em: ago. 2018.

VIANA, C. E. A educomunicação possível: Práticas e teorias da educomunicação revisitadas por meio de sua práxis. In: SOARES, I. O.; VIANA, C. E.; XAVIER, J. B. (orgs.). Educomunicação e suas áreas de intervenção: Novos paradigmas para o diálogo intercultural. São Paulo: APBEducom, 2017, p. 925-943.

VILLELA, H. O. S. Do artesanato à profissão: Saberes de normalistas no Brasil do século XIX. Anais da 26a Reunião Anual da ANPEd - Novo Governo. Novas Políticas?, Poços de Caldas, Minas Gerais, 2003. Disponível em: http://26reuniao.anped.org.br/trabalhos/heloisadeoliveirasvillela.rtf. Acesso em: ago. 2018.

WAISBORD, S. Family tree of theories, methodologies and strategies in development communication. New York: Rockefeller Fundation, 2001.

\section{Sobre a Autora}

Gislene Moreira é professora investigadora da Universidade do Estado da Bahia (Uneb) no Campus de Seabra, Chapada Diamantina. Autora do livro Sertões Contemporâneos. Atua há mais de 20 anos nos temas juventude, semiárido, educomunicação e cultura, junto a movimentos sociais. É doutora em Ciências Sociais pela Flacso, México; mestre em Cultura e Sociedade; e graduada em Comunicação Social pela Uneb.

Recebido: 18 mar. 2019 